Our Nature (2008)6:1-14

\title{
Universal Features in the Singing of Birds Uncovered by Comparative Research
}

\author{
H. Bhattacharya, J. Cirillo, and D. Todt \\ Institute of Biology, Freie Universität, D-12165 Berlin, Germany \\ haimanti@zedat.fu-berlin.de
}

Received: 12.10.2008, Accepted: 23.11.2008

\begin{abstract}
Aside from some exceptions, songbird species differ in the structure of their singing and usually also in the size and performance mode their song repertoires. In the past, most studies concentrated on the species specific differences of singing, and thereby contributed to a better understanding of their diversity. In our approach, however, we focussed on the opposite perspective; i.e. we investigated whether and how far songbirds share structural song properties. To have a solid data base we focussed on four species of thrushes which were famous for their large vocal repertoires. The two Asian bird species were Oriental Magpie Robins (Copsychus saularis) and Shama Thrushes (Copsychus malabaricus), the two European species the Common Nightingale (Luscinia megarhynchos) and the Thrush Nightingale (Luscinia luscinia). The latter were incorporated into a sample 40 other European songbird species (Table 1) serving as a framework for our comparative approach (Figure 2, 4). Besides well-known differences among species, our analyses of song material yielded some remarkably similar relationships between structural and functional song properties, which often were shared even by unrelated species. In particular measures of song durations were usually related to song application during vocal interaction. And, individual variation of song duration was mainly a result of differences in syllable repetition within trilled song sections. Although some of these findings were predicted already by former studies (see Todt, 2004), their essentials can be based now on profound data sets of detailed measurement.
\end{abstract}

Keywords: European Thrushes, Asian Thrushes, Copsychus saularis, C. malabaricus, song structure, signal lengths.

\section{Introduction}

Listening to the singing of birds can be fascinating, and there is a lot of evidence that such fascination extends even into the domain of scientific investigation. The spectrum of different research fields dealing with birdsong is large and ranges from issues such as song learning and development or song production and performance control to issues of song use and social communication (Marler and Slabbelkorn, 2004; Catchpole and Slater, 2008).
The majority of studies have, until now, been concentrated on the accomplishments of particular birds species and - when comparative aspects were concerned emphasized the often astounding vocal diversity across species. Such is clear not only for the acoustical patterns of songs and the repertoire sizes of different oscines species, but can occur also within species (Becker, 1982; Kroodsma, 2004). As a rule this is a consequence of either large 


\section{H. Bhattacharya, J. Cirillo and D. Todt / Our Nature (2008) 6: 1-14}

repertoire sizes developed by individual learning or of geographical separation of populations. To guide the discussion of the latter form of vocal variation Mundinger (1982) distinguished between micro- and macrogeographic characteristics. Pattern differences within populations or between populations that are not completely separated from each other were called microgeographic features. These were distinguished from macrogeographic features which, in contrast, refer to song properties of populations that settle so far apart of each other that their individuals are unlikely to have any contact (Catchpole and Slater, 1995). In addition, geographic distribution of song patterns was treated also in terms of so-called song dialects (Baptista, 1975, 1990; McGregor, 1980; Thielcke, 1987; McGregor and Thompson, 1988).

In this article we illustrate species specific differences paradigmatically for two Asian and two European species. In addition, we advertise a comparative approach which was designed to uncover and document structural song properties shared by different oscines species. Data suggesting such sharing have been reported for several oscines families. Song material of Thrushes (Turdidae) was investigated to elucidate, for example, the mechanisms of song sequencing and performance control (Isaac and Marler, 1963; Todt 1973, 1977; Todt and Wolfgramm, 1975. Hultsch, 1980; Ince and Slater, 1985), whereas material of Paridae (Hailman, 1989; Martens, 1996) or of Finches (Carduelinae; Badyaev et al. (2002) served to illustrate avian Palaearctic speciation.

Another issue has been forwarded by investigators who studied the vocal interactions of songbirds (reviews in Todt and Naguib, 2000; Todt, 2004). When referring to their finding that interacting birds switch between singing and hearing, Todt and Hultsch $(1996,1998)$ postulated that an optimal management of song exchange should favour an evolution of similar song durations and also mechanisms allowing a rapid memory retrieval of songs. From the perspective of information processing, a song should be long enough to convey a distinct message, but at the same time not so long to constrain a sensory check for signals of a neighbor or delay a potential reply (Hultsch et al., 1999).

In this paper, we present results of a study that examined such predictions and additionally investigated some other structural properties of songs, e.g. the repertoire sizes of species, the rules of their song composition and the mode of their song performance. Subjects were two representatives of the Asian avifauna, i.e. the Oriental Magpie Robin (Copsychus saularis) and the Shama Thrush (Copsychus malabaricus) and the two representatives of the European bird community; i.e. the Common Nightingale (Luscinia megarhynchos) and the Thrush Nightingale (Luscinia luscinia). Song data of 40 other randomly selected European oscines birds (Table 1) served as a framework for our comparative approach. By reporting both the methodological procedure and its outcome our paper will hopefully stimulate further ornithologists from different parts of the world to perform similar comparative approaches. As such perspective requires that investigators apply corresponding methods and terms, we will briefly outline also a wellproven concept of song classification subsequently.

\section{Materials and methods}




\section{H. Bhattacharya, J. Cirillo and D. Todt / Our Nature (2008) 6: 1-14}

\section{Materials}

Subjects investigated in this study were two Asian bird species, the Oriental Magpie Robin (Copsychus saularis) and the Shama Thrush (Copsychus malabaricus) and the two European species, the Common Nightingale (Luscinia megarhynchos) and the Thrush Nightingale (Luscinia luscinia)(Figure 1A, B) . Song data of the 40 further European species (Table 1) served as a framework for our comparative approach.

\section{Asian songsters}

Magpie Robins and Shama Thrushes inhabiting in the Indian subcontinent, show similar geographical distributions and sometimes may occur sympatric as well (Grimmett et al., 2000). The vocal material of the Magpie Robins ( $n=5)$ was recorded in Biratnagar, Nepal in the breeding season of 2007 by applying a Sanyo mini-tape recorder with an in-built microphone.

The acoustical material used in the study of Shama Thrushes $(n=24)$ was obtained from the British Library and longer recordings were made at 4 bird breeders at various locations in Germany between March and July 2008. For recording the songs of Shama Thrushes we used a Zoom Corp. H2 Handy Recorder and a Sony TCD5 recorder equipped with external Sennheiser ME-80 microphones.

To prepare the song analyses we appreciated vocal material from different parts of the worlds and provided by the British Library Sound Archive.

\section{European songsters}

Common Nightingales and Thrush Nightingales differ in their geographical distributions (Naquib and Todt, 1998), but may occur sympatric as well. The latter is the case in an area North and East of Berlin/Germany. The material analysed in our study was recorded in Northern Germany (mainly in and around the City of Berlin) before and during the birds' breeding season. The list of species $(n=42)$ is given in Table 1 .

For the recording we used a Sony TCD-6 Walkman equipped with two Sennheiser ME80 microphones. One of them was directed towards a singing bird, whereas the other one served for documenting contextual data or additional information (commentary).

\section{Data analyses}

Recordings were analysed by sound spectrography using the commercial software program 'Avisoft' (R. Specht, Berlin). Sound patterns were sampled and printed as frequency spectrograms (sonagrams). When ever possible, we sampled a total of $1 \mathrm{~h}$ of singing for an individual bird and about $3 \mathrm{~h}$ for a given species.

To examine structural similarity or differences between song patterns, two persons, who were not informed about the "aim of our study" independently did the following analyses. They visually compared spectrographic displays of the recordings and counted the number of vocal patterns belonging to the same type of song. The acoustic precision of most songbirds allowed for an objective assessment of this variable. Our test persons classed two song patterns to the same song-type if these did not differ in (a) their syllables or elements and also (b) the sequential succession of their constituents. Differences in the amount of syllable or element repetitions (trill sections), however, accepted for a given type, and measured as a kind of song variation (Hultsch and Todt, 1998). 


\section{H. Bhattacharya, J. Cirillo and D. Todt / Our Nature (2008) 6: 1-14}

For logistical reasons, i.e. because the amounts of song material available for the various species were too different, statistical data analyses were kept rare and constrained to a calculation of box-plots, or means (+ SDs), or medians (+ quartile), respectively. This procedure followed suggestions of Mundry and Fischer (1998) that are appropriate if samples are too small for asymptotic tests (see also Siegel and Castellan, 1988). Our decision to give the real data in most cases was also substantiated by two further arguments: First, this was necessary for a comparison between our data and the data published by other investigators. Second, a statistical treatment of inter-specific data needs more information about the biological framework of comparison than is at hand currently.

\section{Methods and models guiding birdsong research: an epistemological note}

Our procedure followed a formal perspective, i.e. the singing of birds was treated as a stream of behavior that is specified by a clear-cut alternation of acoustical patterns and silent intervals (pauses). Classification of acoustical patterns was done by first studying the frequency distributions of silent intervals between them. In all inspected cases the distributions were multimodal, i.e. showing a prominent frequency peak below $200 \mathrm{~ms}$ and an other clearly above $500 \mathrm{~ms}$. Accordingly, only patterns that occurred separated by a silent interval of at least 0.5 seconds were called 'songs' (= 'strophes'; see also Todt, 1973; Hultsch, 1980; Thompson et al., 1994). This formal definition of songs invited to describe the singing behaviors of our birds as a structural hierarchy (Hultsch and Todt, 1998). In this order songs form an intermediate hierarchy level. That is, the highest level is given by an episode of singing or a sequence of songs (term: intersong level). On hierarchically lower levels one can distinguish several structural compounds that compose the songs (term: intra-song levels). In a top-down order these are, for example, song sections and element complexes, such as motifs, trills, syllables and elements or notes.

The numbers of both phonetic song constituents and discerned intra-song levels vary a lot across species. Most analyses, therefore, concentrate on the basic level of song organization which is given by the socalled 'song elements'. At this level units are compared and, according to parametric cues or values assessed by frequency spectrography, either told apart or lumped. The pool of classified song elements is then taken to categorize the songs and to class songs with an equal patterning, i.e. songs that differ neither in their syllables or elements nor in the sequential succession of their constituents as representatives of the same type of song. The number of different song-types describes the size of a song repertoire that a given species or individual can perform (Todt, 1968; Lemon and Chatfield, 1971; Shiovitz, 1975, Bondesen, 1979; Kroodsma, 1982; Todt and Hultsch, 1996).

Knowledge about the repertoires of song constituents and songs invite studies on how they are produced and used by given species. Inquiries into the dynamic or the sequential order of vocalisations lead to a rule system called 'procedural hierarchy' (review in Hultsch and Todt, 1998). There are numerous demonstrations that the rules of this kind of hierarchy affect the intrasong level and the inter-song level as well. 


\section{H. Bhattacharya, J. Cirillo and D. Todt / Our Nature (2008) 6: 1-14}

A typical procedural feature of the withinsong structure concerns e.g. the distinction between 'motifs' and 'trills'. 'Motifs' are defined as complexes of elements (notes) that always occur in the same stereotype succession, whereas 'trills' result from a repetition of song constituents, elements or syllables. Another feature is given where many different song-types start with the same introductory element type or a songster has different choices to continue a particular sequence of elements (Todt, 1973; Hultsch, 1980; Naguib and Kolb, 1992). Please note: This within-song property remained a neglected issue of birdsong research. Therefore we will concentrate a new line of study with the Asian thrush species predominantly on this issue.

A procedural hierarchy can be found at the intersong level, too. However, in contrast to the sequencing of song elements, the sequencing of songs reflects a remarkably higher degree of freedom. That is, in principle, no song-type succession is excluded. Nevertheless, one can find preferred sequential permutations of particular types of songs. According to their specific singing styles, song birds species have been classed as either repetitive (schema: A,A,A,A... B,B... C,C,C ...) or versatile songsters (schema: A,B,C,D ...). The first style has been specified also as 'singing with an eventual versatility' and is common e.g. in Chaffinches (Fringilla coelebs) and Great Tits (Parus major). The second one in contrast, was called 'singing with an immediate versatility' (Kroodsma, 1982) and is typical e.g. for Eurasian Blackbirds (Turdus merula) and Common Nightingales (Luscinia megarhynchos).

\section{Terminology}

Most birdsong studies deal mainly with vocal patterns corresponding to what above has been termed SONG. Temporal characteristics of vocal patterns performed by the two Asian thrushes suggest to accept an other structure as basic patterns here, namely the MOTIF. In many species, motifs occur as acoustical components of songs, however, in our new study they seem to establish a special level of behavioural organisation (Todt, 1986).

\section{Results}

Our results are outlined in three subsections referring to (a) the size of vocal repertoires and both (b) temporal features and (c) sequential features of song organisation.

\section{Size of vocal repertoires}

Procedures of repertoire assessment confirmed that sizes differed extremely across species (see Todt et al., 1981; Kroodsma, 2004). The largest amount of variation was found for element types. It ranged from one extreme, observed e.g. in individual Chiffchaffs (Phylloscopus collybita) with 2 or 3 element types per individual, to another one documented e.g. for Common Nightingales where a given individual may sing more than 1000 different element types. The size of song repertoires, in contrast, ranged between 3 song-types, found e.g. in individual Great Tits (Parus major), and more than 200 songtypes found in some Nightingales (Hultsch $e t$ al., 1999; Figure 2).

Our two Asian candidates fitted well into this variety. Individual Magpie Robins showed repertoires of 8 or a bit more types of motifs and such were composed by about 100 types of elements. Individual Shama Thrushes, on the other hand, performed 32 or more types of motifs that were composed 


\section{H. Bhattacharya, J. Cirillo and D. Todt / Our Nature (2008) 6: 1-14}

by about 800 to 1000 types of elements (Figure 3).

Please note: In Magpie Robins we have used the term MOTIF and SONG as well (Bhattacharya et al., 2007, Figure 3). Here, often one motif alone composes a song, i.e. a pattern separated by the next following song (motif) by a pause of a few seconds. In Shama thrushes the structure of both acoustically filled and silent intervals can be so different that we did not yet define what could represent a SONG here.

\section{Temporal features of song organisation}

Procedures of time domain analysis provided two main results. First, by evaluating the durations of silent intervals our data confirmed what had been documented already by many other studies; i.e. that the length of these intervals was either below or above 0.5 s (see e.g. Hultsch, 1980; Kroodsma, 1982). The vast majority of silent intervals were shorter than $0.5 \mathrm{~s}$ and these pauses separated elements within a given sequence of vocalization. Interestingly, this finding was true for all species included in our study. Silent intervals longer than $0.5 \mathrm{~s}$, in contrast, separated successive larger compounds, i.e. sequences of elements such as motifs or songs. These sort of pauses could differ extremely among species. Interestingly, however, they could also vary within species or even among different singing performances of a given individual, e.g. depending on the state or status of a bird.

In a second step of analysis we investigated the duration of element sequences. Aside some minor differences among species, these measures showed less variation in most cases, i.e. the lengths ranged between $1 \mathrm{~s}$ and $15 \mathrm{~s}$. Nevertheless, we found a few species where much longer element sequences were common (Figure 4). Following a suggestion of Hultsch (1980) the latter were classed as 'course singers' and also characterized as bird species that do not engage in mutual interaction by songs (see also Todt et al., 1981). Parallely, we were able to characterize the birds with element sequences below $15 \mathrm{~s}$ as species that frequently engage in such interactions. In addition, only these shorter sequences were accepted as typical songs (see 2.3). Comparison of song durations revealed a clear frequency peak for measures around 3 to $4 \mathrm{~s}$ (Figure 4).

Our two Asian candidates fitted well into this variety. Magpie Robins showed a mean duration of motifs/songs of $3 \mathrm{~s}$ (Figure 5), whereas Shama Thrushes performed longer patterns. That is, their vocalisations were preferentially composed by several types of motifs and lasted for about $6 \mathrm{~s}$ then (Figure 5).

\section{Sequential features of song organisation}

In third step of analysis we investigated the sequential composition of vocal patterns with a mean duration of 3 to $6 \mathrm{~s}$ (Figure 4, 5). The sequential features of this organisation showed a large variety when compared across species. Above all, they allowed to distinguish three classes of pattern organisation:

(a) Patterns composed by a sequence of element types without any repetition (= MOTIFs),

(b) Patterns composed by a repetition of element or syllable types (= TRILLs),

(c) Patterns composed by a combination of motifs and trills (= COM-PATTs).

Birds belonging to class (a) were rare, but e.g. given by Eurasian Blackbirds (Turdus 
H. Bhattacharya, J. Cirillo and D. Todt / Our Nature (2008) 6: 1-14

Table 1. List of bird species included in this study

Acrocephalus arundinaceus, Acrocephalus schoenobaenus, Anthus trivialis, Carduelis flammea, Certhia
brachydactyla, Certhia familiaris, Emberizia calandra, Emberiza citronella, Emberiza hortulana, Emberiza
schoeniclus, Erithacus rubecula, Ficedula hypoleuca, Ficedula parva, Fringilla coelebs, Luscinia luscinia,
Luscinia megarhynchos, Melospiza melodia, Motacilla cinerea, Parus ater, Parus caeruleus, Parus major,
Parus montanus, Parus palustris, Phoenicurus ochruros, Phoenicurus phoenicurus, Phylloscopus collybita,
Phylloscopus sibilatrix, Phylloscopus trochilus, Prunella modularis, Regulus ignicapillus, Regulus regulus,
Remiz pendulinus, Saxicola rubetra, Saxicola torquata, Sturnus vulgaris, Sylvia atricapilla, Sylvia borin,
Sylvia communis, Sylvia curruca, Troglodytes troglodytes, Turdus merula, Turdus philomelos, Acrocephalus
arundinaceus, Acrocephalus schoenobaenus, Anthus trivialis, Carduelis flammea,Certhia brachydactyla,
Certhia familiaris
Certhia familiaris
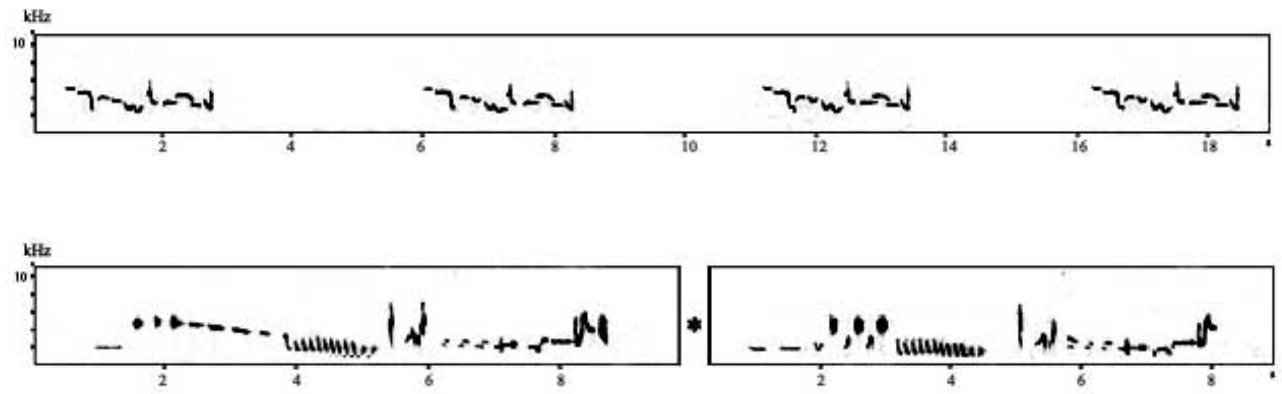

Figure 1. Frequency spectrograms illustrating the vocal pattern of two closely related Asian song thrushes. Top: Magpie Robins. Bottom: Shama Thrush.


Figure 2. Frequency spectrograms illustrating the vocal pattern of two closely related Asian song thrushes. Top: Thrush Nightingale. Bottom: Common Nightingale. 
H. Bhattacharya, J. Cirillo and D. Todt / Our Nature (2008) 6: 1-14

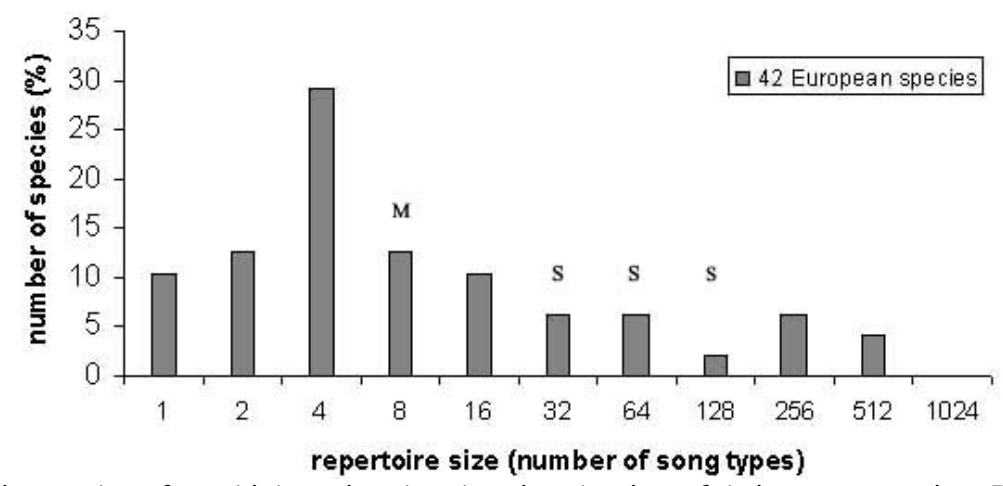

Figure 2. Relative number of songbird species plotted against the sizes of their song repertoires. Data refer to song material collected in Northern Germany $(n=42)$. M: Magpie Robin, S: Shama Thrush.

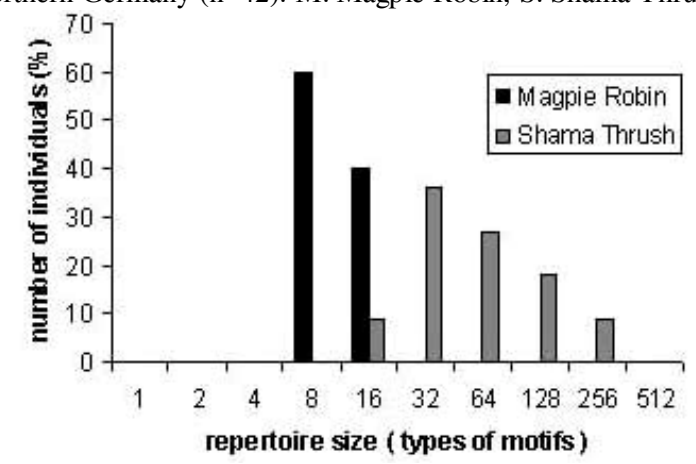

Figure 3. Relative number of individuals Magpie Robins (black) and Shama Thrushes (grey) plotted against the number of motif types. Data of song material for Magpie Robins ( $n=5)$ was in the wild (Nepal) and Shama Thrushes ( $\mathrm{n}=12)$ was in captivity (Germany).

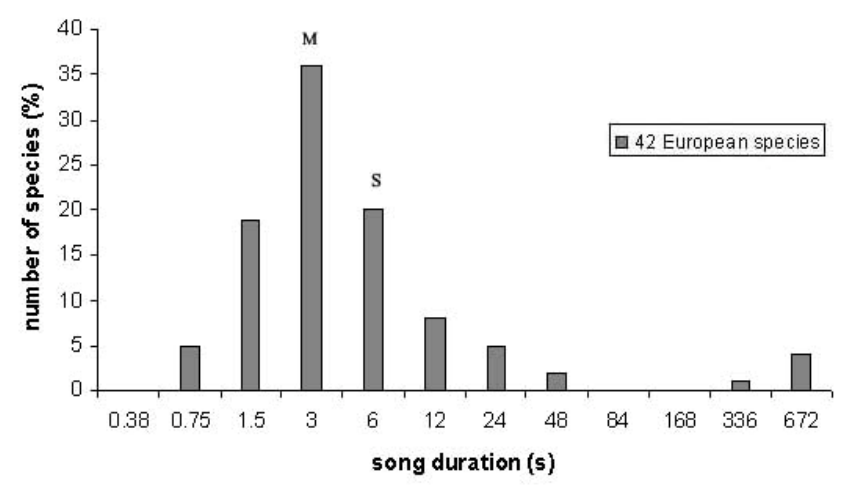

Figure 4. Relative number of songbird species plotted against the duration of their song types. Data one value only (mean). M: Magpie Robin, S: Shama Thrush. 
H. Bhattacharya, J. Cirillo and D. Todt / Our Nature (2008) 6: 1-14
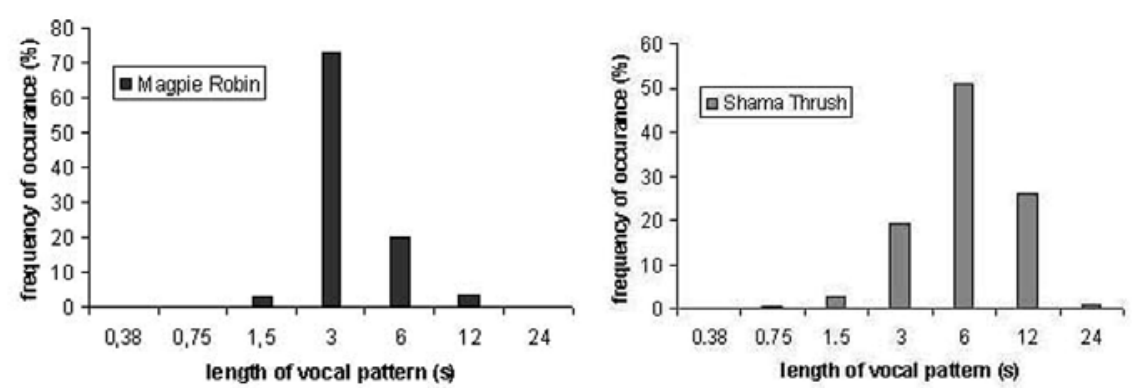

Figure 5. Relative number of individuals plotted against the duration of vocal patterns (geometric scale of time classes).

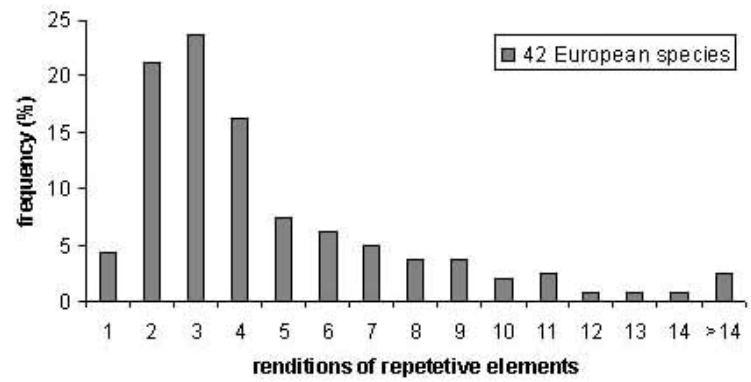

Figure 6. Amount of successive renditions of a given type of song element. Data refer to element types only which composed the trill section of Nightingale songs and thus used to be performed in a reiterated manner (see Fig. 1). Note: Position 1 in the graph indicates that such element types only rarely occured as a solitary event.
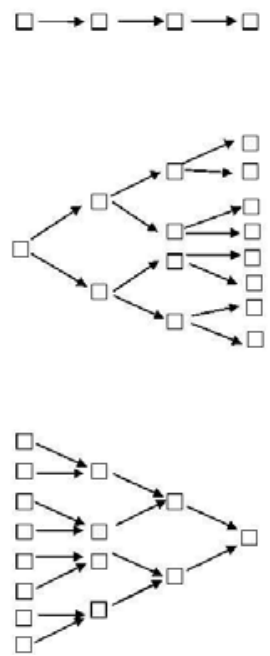

Figure 7. Illustration of three alternative flow charts that describe e.g. an element type succession in the singing of birds. Top: subfluent schema (one-to-one model) Middle: diffluent schema (one-to-many model) Bottom: confluent schema (many-to-one model). 


\section{H. Bhattacharya, J. Cirillo and D. Todt / Our Nature (2008) 6: 1-14}

merula) and the Magpie Robin (Copsychus saularis). Examples of class (b), were much more frequent and given e.g. by the Song Thrush (Turdus philemos) or many songsters of the Paridae family. Class (c) bird species were wide-spread in European areas and in Asia at least represented by the Shama Thrush.

Please note: In the past many species of classes (a) and (c) we investigated in terms of element type successions within patterns or songs. The results had been described by flow charts also known as 'element syngraphs' (Todt 1973; Hultsch and Todt 1998). Such charts summarise all connections of element types within the repertoire of a given bird in terms of both the direction and the frequency of successions. As this sort of analysis was not yet performed with our two Asian thrush species, we will postpone a more detailed treatment of this inquiry.

In another step of analysis, we investigated the rules of element type repetition within trills. That is, we counted the number of reiterations of a given type of element of syllable and concentrated especially on variations of these measures (Figure 6). Our analysis revealed rules that were remarkably consistent across all species belonging to classes (b) and (c), and can be listed as follows: First, aside preferred amounts of repetitions songsters could extend the trills. Such instances occurred in particular situations and thus pointed to a functional role of the variation. Second, raised repetition frequencies were always linked with a temporal prolongation of a given vocal sequence and sometimes also with subtle changes of single unit parameters, e.g. the pitch or the volume. This phenomenon is another facet of singing in birds which clearly merits a further investigation (see Hultsch and Todt, 1998).

\section{Discussion}

Aside the well-known differences among species, our study documented a set of structural song properties, which were shared even by taxonomically unrelated songbirds. Above all, most species shared some temporal features of song organization, e.g. the durations of silent intervals within songs or other sequences of vocal elements as well as the durations of songs that formed a clear frequency peak between $3 \mathrm{~s}$ and $<6 \mathrm{~s}$. In addition, many species shared also some features of sequential song organisation. Such was particularly evident for the expression of trills, which regularly showed individual variations in length resulting from sporadic differences in syllable repetitions. We conclude that the majority of these interspecific similarities reflect a functional adaptation that evolved because they two major advantages: first they promote rapid song retrieval from memory and second they allow territorial songsters to improve their strategies of vocal interaction. Although this conclusion is in line with predictions of other authors (see e.g. Hultsch et al. 1999), it merits a more detailed discussion.

\section{Structural universals in birdsong}

Research requires switching between analytic and synthetic procedures. Given the fascinating diversity of avian singing accomplishments, it seems just reasonable to not only study the differences among species, but from time to time also search for similarities or features which species have in common and thus can be regarded as universals. We suggest that some of the features summarized above, at least the temporally constrained song duration of songs, can be interpreted as such a universal. 


\section{H. Bhattacharya, J. Cirillo and D. Todt / Our Nature (2008) 6: 1-14}

To further elaborate the cited explanation of this structural universal we outline some relevant arguments. First, the hypothesis originally forwarded by Todt and Hultsch $(1996,1998)$ and predicting that songs serve for an optimal vocal interaction and thus should be long enough to convey a distinct message, but at the same time not so long to constrain a sensory check for signals of a neighbor or delay a potential reply, is well confirmed. Findings supporting this, were reviewed by Todt and Naguib (2000). Aside aspects of functional adaptation, there are data providing more direct evidence that song durations mirror the birds' switching between singing and hearing. It was documented for Heuglin's Robinchat (Cossypha Heuglini), a dueting species of the African tropics. During solo singing males sing temporally extended sequences of elements, but they split the strings into segments of about $3 \mathrm{~s}$, when engaging into vocal interactions with territorial neighbors (Todt, 1971). With such aspects as a reference, we conclude that also the silent intervals occurring within songs play a role in communication. Our argument is that their consistently short duration helps an addressed conspecific to readily recognize whether a perceived element sequence continues or has been ended, respectively. It would be interesting to study these aspects also with Shama Thrushes now, because their singing styles are often quite similar to those of solo-singing Robinchats.

Birdsong is a learned signal behavior. Its development is guided, however, not only by individual experience, but species-specific predispositions too (Marler, 1979). An example of what this means can be observed during early developmental stages, i.e. when young birds use to practice their early singing accomplishments (Marler and Peters, 1987;
Geberzahn and Hultsch, 2004). During the stages of 'plastic singing', individuals of all species perform long element sequences, and only later in life do individuals cut such sequences into segments, which show the species typical length of songs. Predispositions can also influence what young birds preferentially memorize and which of the memorized learning stimuli they finally keep in their repertoires when using their songs in territorial contests (Marler and Nelson, 1992). As the particular patterns of their songs are acquired by vocal imitation, they depend directly on the pool of learning stimuli to which young birds had access. We assume that the composition of such pools can produce certain differences as well as distinct similarities, and that these can occur not only among individuals but species too. Evidence for the latter has been documented for Common Nightingales who normally perform their songs with immediate versatility, but can to sing similar to a Chaffinch if they had been presented with a learning regime composed by reiterated master song-types (Hultsch, 1991).

With these aspects as a reference, we presume that features of avian singing which bird species share reflect similar mechanisms involved in the song control system of birds (Doupe, 1993; Nottebohm, 1993). A core mechanism which could play a role here, is the birds' song memory and, in species that develop and use large vocal repertoires, also a mechanism regulating an expedient memory retrieval of song patterns (reviews in Marler and Slabbekoorn, 2004). Currently, however, it is too early to say whether and how far the postulated mechanisms may indeed generate similar effects in different species of songbirds. 


\section{Open question}

The structural properties of birdsong encompass much more facets than we have treated in this article. From our perspective there is one of them which predominantly merit a further investigation in the studied Asian thrushes. The questions concerns what usually is known as "procedural hierarchy" (Figure 7; Todt, 1986; see also Bhattacharya et al., 2007).

In European songbirds the structure of vocal patterns is mainly following a solofluent schema or a diffluent schema (Todt and Hultsch, 1980; Hultsch et al., 1999). We have some evidence suggesting that at least the vocalisations of Shama Thrushes could follow a confluent schema. Thus we are asking now: Is this suggestion correct? And, if yes, what does this mean for the song performance control of Shama Thrushes? Could a "confluent decision flow" as illustrated in Figure 7 explain the famous vocal virtuosity of this Asian bird species? We anticipate that answers to such questions will be available before spring 2009.

\section{Acknowledgements}

We thank the British Library for helping us with recordings of Shama Thrush vocalisations and so allowing us to begin the study a few months earlier than expected. The main part of the study was based on recordings done ourselves, either in Nepal or in the aviary facilities of some German bird breeders. Many thanks go especially to Ralf Kempa, Herbert Witt, Thomas Schütt and Andre Zamzow. Finally we are grateful to the Alexander von Humboldt Foundation for providing the financial support to Dr. H. Bhattacharya and to Constance Scharff, Henrike Hultsch and Silke Kipper who offered a substantial cooperation in birdsong research.

\section{References}

Badyaev, A.V., G.E. Hill and B.V. Weckworth 2002. Species divergence in sexually selected traits: increase in song elaboration is related to decrease in plumage ornamentation in finches. Evolution 56: 412-419.

Baptista L.F. 1990. Dialectal variation in the raincall of the chaffinch (Fringilla coelebs). Vogelwarte 35: 249-256.

Baptista, L.F. 1975. Song dialects and demes in sedentary populations of the white-crowned sparrow (Zonotrichia leucophrys nutalli).Univ. Calif. Publ. Zool. 105: 1-52.

Becker, P.H. 1982. The coding of species specific characteristics in bird sound. In: Acoustic communication in birds (Eds. D.E Kroodsma and E.H Miller). Academic Press, New York. pp. 213252.

Bhattacharya, H., J. Cirillo., B.R. Subba and D. Todt 2007. Song performance rules in the oriental Magpie Robin (Copsychus saularis). Our Nature 5: 113.

Bondesen, P. 1979. The hierarchy of bioacoustic units expressed by a phrase formula. Biophon. 6: 2-6.

Catchpole, C.K. and P.J.B. Slater 1995. Bird song: biological themes and variations. Cambridge Univ. Press, Cambridge.

Doupe, A. 1993. A neural circuit specialized for vocal learning. Curr. Opin. Neurobiol. 3:104-111.

Geberzahn, N. and H. Hultsch 2004. Rules of song development and their use in vocal interactions by birds with large repertoires. An. Acad. Bras. Cienc. 76: 209-218. 


\section{H. Bhattacharya, J. Cirillo and D. Todt / Our Nature (2008) 6: 1-14}

Grimmett, R., C. Inskipp and T. Inskipp 2000. Birds of Nepal. A \& C Black, London.

Hailman, J.P. 1989. The organization of major vocalizations in the Paridae. Wilson Bull. 101: 305-343.

Hultsch, H. 1980. Beziehungen zwischen Struktur, zeitlicher Variabilität und sozialem Einsatz im Gesang der Nachtigall, Luscinia megarhynchos. FU Berlin ( $\mathrm{PhD}$ thesis).

Hultsch, H. 1991. Early experience can modify singing styles - evidence from experiments with nightingales, Luscinia megarhynchos. Anim. Behav. 43: 883889.

Hultsch, H. and D. Todt 1998. Hierarchical learning and development of song. In: Animal Cognition in Nature (Eds. I. Pepperberg, R. Balda and E. Kamil). Academic Press, N.Y. pp. 275-303.

Hultsch, H., R. Mundry and D. Todt 1999. Learning, representations and retrieval of rule related knowledge in the song system of birds. In: Learning: rule extraction and representation (Eds. A.D Friederici and R. Menzel. Walter de Gruyter). Berlin and New York. pp. 89115.

Ince, S.A and P.J.B. Slater 1985. Versatility and continuity in the songs of thrushes Turdus spp. Ibis 127: 355-364.

Isaac, D and P. Marler 1963. Ordering of sequences of singing behaviour of mistle thrushes in relationship to timing. Anim. Behav. 11: 179-188.

Kroodsma, D.E. 1982. Song repertoires: problems in their definition and use. In: Acoustic communication in birds (Eds. D.E. Kroodsma and E.H. Miller). Academic Press, New York. pp. 125146.
Kroodsma, D.E. 2004. The diversity and plasticity of birdsong. In: Nature's music: the science of birdsong (Eds. P. Marler and H. Slabbekoorn). Elsevier Academic Press, San Diego. pp. 108131.

Lemon, R.E. and C. Chatfield 1971. Organization of song in Cardinals. Anim. Behav. 19: 1-17.

Marler, P. and D. Nelson 1992. Neuroselection and song learning in birds: species universals in a culturally transmitted behavior. Neurosciences 4: 415-423.

Marler, P. and H. Slabbekoorn 2004. Nature's music: the science of birdsong. Elsevier Academic Press, San Diego. pp 108-131.

Marler, P. and S. Peters 1987. A sensitive period for song acquisition in the song sparrow, Melospiza melodia, a case of age-limited learning. Ethology 76: 89100.

Martens, J. 1996. Vocalization and speciation of palearctic birds. In: Ecology and evolution of acoustic communication in bird (Eds. D.E. Kroodsma and E.H. Miller). Cornell Univ. Press, Ithaka, New York. pp. 221240.

McGregor, P.K. 1980. Song dialects in the corn bunting (Emberiza calandra). Z. Tierpsychol. 54: 285-297.

McGregor, P.K. and D.B.A. Thompson 1988. Constancy and change in local dialects of the corn bunting. Ornis Scand. 19: 153-159.

Mundinger, P.C. 1982. Microgeographic and macrogeographic variation in acquired vocalizations in birds. In: Acoustic communication in birds (Eds. D.E. Kroodsma and E.H.) Miller 
Academic Press, New York. pp. 147208.

Mundry, R. and J. Fischer 1998. Use of statistical programs for nonparametric tests of small samples often leads to incorrect $P$ values: examples from Animal Behaviour. Anim. Behav. 56: 256-259.

Naguib, M. and H. Kolb 1992. Vergleich des Strophenaufbaus und der Strophenabfolgen an den Gesängen von Sposser (Luscinia luscinia) und Blaukehlchen (Luscinia svecica). J. Ornithol. 133:133-145.

Naquib, M. and D. Todt 1998. Recognition of neighbours' song in a separate species with large and complex song repertoires: Thrush Nightingale. Journal of Avian Biology. 29: 155-180.

Nottebohm, F. 1993. The search for neural mechanisms that define the sensitive period for song learning in birds. Neth. J. Zool. 43: 193-234.

Shiovitz, K.A. 1975. The process of speciesspecific song recognition by the indigo bunting (Passerina cyanea). Behaviour 55: 128-179.

Siegel, S. and N.J. Castellan. 1988. Nonparametric statistics for the behavioral sciences. McGraw-Hill, New York.

Thielcke, G. 1987. Langjährige Dialektkonstanz beim Gartenbaumläufer (Certhia brachydactyla). J. Ornithol. 128: 171-180.

Thompson, N.S., K. LeDoux and K. Moody 1994. A system for describing bird song units. Bioacoustics 5: 267-279.

Todt, D. 1971. Zur gesanglichen Reaktion der Schmätzerdrossel Cossypha heuglini. Behaviour 38: 146-153.

Todt, D. 1973. Biologisch-kybernetische Analyse der Komposition des Gesangs verschiedener Vögel. Nova Acta Leopoldina 208: 311-331.

Todt, D. 2004. From birdsong to speech: a plea for comparative approaches. Annals of the Brazilian Academy of Sciences 76: 1-8.

Todt, D. and H. Hultsch 1996. Acquisition and performance of repertoires: ways of coping with diversity and versatility. In: Ecology and evolution of acoustic communication in birds (Eds. D.E. Kroodsma and E.H. Miller). Cornell Univ. Press, Ithaka, New York. pp 7996.

Todt, D. and H. Hultsch 1998. How songbirds deal with large amounts of serial information: retrieval rules suggest a hierarchical song memory. Biol. Cybern. 79: 487-500.

Todt, D. and J. Wolfgramm 1975. berpru * fung von Steuerungssystemen zur Strophenwahl der Amsel durch digitale Stimulierung. Biol. Cybern. 17: 109127.

Todt, D. and M. Naguib 2000. Vocal interactions in birds: the use of song as a model of communication. Adv. Stud. Behav. 29: 247-296.

Todt, D., H, Hultsch and F.P Duvall 1981. Behavioural significance and social function of vocal and non-vocal displays in the monogamous duet-singer Cossypha heuglini H. Zool. Beitr. 27: 422-448. 